\title{
Evaluation of Correlation between the Cross- sectional Area of Posterior Cervical Extensor Muscles and Cervical Sagittal Alignment in Patients with Hirayama Disease
}

\section{Ye Tian}

Department of Orthopedics, Huashan Hospital, Fudan University, Spinal Center Fudan University Lin Xie

Department of Orthopedics, Huashan Hospital, Fudan University , Spinal Center Fudan University Jianyuan Jang

Department of Orthopedics, Huashan Hospital, Fudan University , Spinal Center Fudan University Hongli Wang ( $\nabla$ wanghongli0212@163.com)

Department of Orthopedics, Huashan Hospital, Fudan University, Spinal Center Fudan University

\section{Research Article}

Keywords: Hirayama disease,Cervical spine,Posterior cervical extensor muscles, Cross-sectional area,Local kyphotic deformity

Posted Date: September 7th, 2021

DOI: https://doi.org/10.21203/rs.3.rs-827562/v1

License: (a) (i) This work is licensed under a Creative Commons Attribution 4.0 International License. Read Full License 


\section{Abstract}

Purpose: To assess correlation between the cross-sectional area (CSA) of posterior cervical extensor muscles (PCEMs) and the cervical sagittal alignment in Hirayama disease (HD) patients.

Methods: We analyzed the MRI (Magnetic resonance imagine) T2WI and X-rays of 60 male HD patients who visited our hospital from June 2017 to February 2020. Their mean age was $18.95 \pm 1.67$ years (range 16-22 years). MRI image is used to measure the CSA of cervical PCEMs. The ratio of muscle CSA to vertebral body areas (VBA) at the same level is defined as R-CSA. Cervical sagittal alignment includes $\mathrm{C}_{2-7}$ cobb angle, $\mathrm{T} 1$ slope, and $\mathrm{C}_{2-7}$ sagittal vertical axis (SVA). The geometric center of the $\mathrm{C}_{3-6}$ vertebral body was determined using the line connecting the $C_{2}$ inferior endplate and the $C_{7}$ upper endplate. When located behind the line, it is defined as a "Local kyphotic deformity" (LKD). The number of vertebral bodies involved in kyphotic deformity was determined by Local kyphosis angle (LKA) measured. Spearman correlation analysis $(a=0.05)$ was used to determine the relationship between R-CSA and sagittal parameters.

\section{Results:}

Spearman correlation test revealed that R-CSA negatively correlated with T1S $(S=0.34, p=0.01)$ and LKA $(\mathrm{S}=0.44, p=0.01)$ but did not correlated with $\mathrm{C} 2-\mathrm{C} 7 \mathrm{cobb}$ angle $(\mathrm{S}=0.20, p=0.12)$ or $\mathrm{C} 2 \mathrm{-C} 7 \mathrm{SVA}(\mathrm{S}=-0.17$, $p=0.46) .(p \otimes 0.05)$

Conclusions: In Hirayama disease, the CSA of PCEMs is related to T1s and LKA and exercising the PCEMs should be given enough attention.

\section{Introduction:}

Hirayama disease (HD), first reported in 1959(1), is a spinal cord-derived upper extremity muscular atrophy disease that commonly affects adolescent males. Although HD was thought to be most prevalent among Asians, cases have been reported in many parts of the world(2-5). A high number of cases is expected in the next few decades. There is evidence that early surgical intervention is effective in managing HD(6-9). Thus, spine surgeons will be expected to master HD diagnosis and treatment. In HD patients, the sagittal sequence of cervical vertebra is abnormal and the cervical vertebra's range of motion is increased(10). Here, we sought to uncover the causes for this.

Neck muscles are crucial in the maintenance of cervical spine stability(11). In normal spines, static sagittal balance is the spine's physiological alignment by muscle forces(12). Hence, spine sagittal balance is an important factor affecting patient quality of life and surgery outcome(13). The cervical spine is the most flexible part of the spine and provides supports the skull to maintain horizontal fixation. Numerous factors affect cervical sagittal balance, especially muscle strength, and extensor muscles have been shown to be crucial for this(14). However, the cause of cervical sagittal alignment abnormality in HD is unknown. We speculate that it is associated with the strength of posterior cervical extensor muscles. It 
is known that muscle CSA positively correlates with muscle strength $(15,16)$. Manually delineating regions of interest (ROI) in extensor posterior cervix on axial MRI and then measuring the CSA of the PCEMs has been shown in many studies with good consistency $(17,18)$.

Here, we investigated correlation between the cervical sagittal alignment and PCEMs and examined the importance of cervical muscle training in the treatment of HD.

\section{Materials And Methods:}

The study was approved by the institutional ethics board (No:2021-582, Institutional Review Board of Huashan Hospital, Fudan University) and performed in accordance with the ethical standards of the 1964 Declaration of Helsinki as revised in 2000 and those of Good Clinical Practice. All patients gave written informed consent. Participants under the age of 16 have obtained written informed consent from their parents or guardians.

\section{Patients and methods}

The study involved male HD patients diagnosed at our hospital from June 2017 to February 2020. The diagnostic criteria is the clinical diagnosis of Hirayama disease $(1,19-22)$, these include adolescent onset, manifestation of unilateral upper limb muscle weakness, and muscle atrophy of the forearm and hand. Accompanying symptoms include cold paralysis and tremor-like movement of fingers when stretched. Some patients with a longer course may have active or hyperactive tendon reflexes of the lower limbs, as well as positive Hoffmann's signs and other manifestations. A total of 60 male patients with a mean age of 18.95 years (range: $16-22$ years) who met the criteria were included in the study.

\section{Radiographic evaluations}

Muscle cross-sectional area was measured by 2 independent spine surgeons(Table 1), Tian and Xie, using the Image $\mathrm{J}$ (National Institutes of Health, America) to measure ROI (Figure 3 ) on the CSA of the PCEMs based on the techniques used in previous studies(23). Selected images were all T2-weighted magnetic resonance images parallel to the $\mathrm{C}_{5}-\mathrm{C}_{6}$ intervertebral disc axis MR. PCEMs include deep extensors (DEs) and superficial extensors (SEs). The ROI is defined as the vertical line of the lateral edge of the bilateral facet joints. The CSA of the endplate at the same level was used as the c5-c6 vertebral body area, and the bilateral CSA measured and recorded in $\mathrm{mm}^{2}$. Examination was done using 1.5T MRI machine (Siemens, Germany) to acquire a neutral MRI of the cervical spine with the patient laying in supine position.

Cervical sagittal parameters were measured on upright cervical radiographs(Figure 1 ). $C_{2}-C_{7}$ Cobb angle is created by a line parallel to the inferior endplate of the $C_{2}$ vertebra and a line parallel to the inferior endplate of the $\mathrm{C}_{7}$ vertebra. SVA is the vertical distance from the plumb line of the geometric center of the 
$\mathrm{C}_{2}$ vertebra to the posterior superior corner of the $\mathrm{C}_{7}$ vertebra. $T 1 \mathrm{~s}$ is the angle between the horizontal and the superior endplate of T1s vertebra(24-26). The definition for "Local kyphotic deformity" was used to determine the upper/lower end vertebras on upright cervical radiographs. Next, a vertical line was drawn at the upper/lower end vertebra endplate extension lines. The resulting angle between the 2 vertical lines is the "Local kyphosis angle" (LKA) and was measured using the Cobb method. When the extension line of the vertebral endplate intersected behind the neck, the cobb angle was given positive value and when the extension line of the vertebral endplate intersected at the front of the neck, the cobb angle was given a negative value.

\section{Statistical analysis}

STATA version 16.0 (StataCorp) was used for statistical analysis. All parametric results were expressed as mean \pm standardized deviations. Spearman rank correlations were used for correlation statistical analysis. $P<0.05$ indicated statistical significance. The independent $\mathrm{t}$ test was used to compare differences of all these data(without LKA) between "Local kyphotic deformity" and "non- Local kyphotic deformity".

\section{Results:}

A total of 60 male patients with a mean age of (18.95 1.67$)$ years (range:16-22) were included in the study. The mean height was $174.2 \pm 6.41(\mathrm{~cm})$ (range:150-188). The mean BMI(Body mass index) was 21.25 \pm 2.95 . The duration of disease was 4-6 months. After our research, we divided the patients into two groups: Non-LKD $(n=29)$ and $\operatorname{LKD}(n=31)$. There were no differences in age, height, weight and $B M I$ two groups $(p>0.05)$.(Table3)

The area parameters were VBA: $384.623 \pm 64.70 \mathrm{~mm}^{2}$.CSA: $1348.98 \pm 236.44 \mathrm{~mm}^{2}$. R-CSA:

$3.60 \pm 0.87 \mathrm{~mm}^{2}$.Cervical sagittal parameters were T1 slope: $16.62 \pm 5.96, \mathrm{C} 2-\mathrm{C} 7 \mathrm{SVA}: 17.40 \pm 8.73, \mathrm{C} 2-\mathrm{C} 7$ Cobb: 5.28 \pm 12.43 (Table2) .Of these, 31 had "LKD" : $C_{3-5}: 2, C_{4-6}: 7, C_{3-6}: 22$. LKA : -9.82 $\pm 6.33 . C_{2-7}$ cobb angle of group LKD is smaller than group Non-LKD and VBA of group Non-LKD is smaller than group LKD. There is no difference in other parameters between the two groups(Table 3).

Correlation analyses were done using Spearman test. R-CSA negatively correlated with T1S ( $\mathrm{s}=0.3362$, $p=0.0086)$ R-CSA negatively correlated with LKA ( $(s=0.4382, p=0.0137)$. R-CSA did not correlate with $\mathrm{C}_{2}-\mathrm{C}_{7}$ cobb angle ( $\mathrm{s}=0.2029, p=0.1199)$ or $\mathrm{C}_{2}-\mathrm{C}_{7}$ SVA $(\mathrm{s}=-0.1701, p=0.4586)$.(Figure2)

\section{Discussion:}

\section{Posterior cervical extensor muscles and sagittal parameters}


Currently, the relationship between cervical sagittal alignment and PCEMs has been paid attention to by many scholars(27-29). Past studies show that in some patients non-Hirayama disease (HD)(30), cervical sagittal alignment is abnormal and is accompanied by PCEMs atrophy. There is a paucity of research on HD. In our study, we found similar results in HD patients. We have utilized imaging parameters to describe the cervical sagittal alignment and used muscle cross-sectional area represent muscle strength. These methods have been used in previous studies $(15,17)$.

\section{Strong PCEMs maybe lead to better cervical sagittal alignment}

Cervical muscle strength is lower in HD patients relative to normal people, and there is a mismatch between flexor muscles and extensor muscles(23). Change in extensor muscle strength may affect cervical sagittal alignment. T1s is an important cervical sagittal parameter and is related to the thoracic entrance angle $(31,32)$. The degree of motion of the thoracic vertebra is small and prone to change. Our data show that T1s was closely related to the area of the PCEMs. Since T1s was a relatively fixed value(33), it was closely related to the entrance angle of the thoracic cage and was not easily changed by changes in the cervical spine. Our data suggest that T1s may not be affected by change in the strength of the PCEMs, but the larger the T1s, the more cervical vertebra is required to participate in lordosis in order to maintain horizontal gaze and larger cervical lordosis $(\mathrm{CL})$ requires stronger support of the PCEMs. At present, the relationship between T1s and the strength of PCEMs is not clear in HD patients. In future, it may serve as an indicator of posterior cervical muscle strength. There was no obvious correlation between SVA and PCEMs strength. Lee et al. showed that T1s, CL and SVA are closely related, and that SVA has a compensatory role between T1s and CL(33). Thus, there was no clear correlation between SVA and PCEMs strength.

The $\mathrm{C}_{2}-\mathrm{C}_{7}$ Cobb angle was smaller than reported by past studies but it did not significantly correlate with PCEMs strength(34-36). These figures are influenced by factors like age and posture. According to the previous study(37), we predicted that Cobb angle might be closely related to the strength of PCEMs but corresponding results were not obtained after measurement. After analysis, since the number of vertebrae in $\mathrm{C}_{2}-\mathrm{C}_{7}$ did not match the measurement site of muscle, we only measured the muscle's CSA at the $\mathrm{C}_{5}-\mathrm{C}_{6}$ level, which does not represent muscle strength of the entire cervical spine. There was no obvious correlation between the muscle area and the $\mathrm{C}_{2}-\mathrm{C}_{7}$ Cobb angle. Therefore, we defined "Local kyphosis" and measured the local kyphosis angle. This analysis showed that that in HD patients, LKD tended to occur in the $\mathrm{C}_{3-6}$ segment and was closely related to the CSA of PCEMs (the greater the extensor strength, the smaller the LKA, Figure2d). Meanwhile, we found that the $C_{2}-C_{7}$ Cobb angle of LKD patients was smaller than that of non-LKD patients (Table 3). There was significant correlation between PCEMs strength and cervical spine kyphosis. Most of the vertebrae involved in kyphosis are $\mathrm{C}_{3}-\mathrm{C}_{6}$, and PCEMs atrophy can cause abnormal cervical curvature, especially of the extensor. In HD patients, cervical muscle CSA is smaller than in normal people, and there is flexor and extensor muscle mismatch(23). We 
speculate that the atrophy of cervical posterior extensor muscle in HD is a reason for abnormal cervical sagittal alignment.

\section{Treatment considerations for HD}

We for the first time show association between posterior cervical extensor muscle and cervical kyphosis in HD patients. Neck muscles are crucial in maintaining stability of the cervical spine. The relationship between neck muscles and cervical spine curvature has been shown in some patients with non-Hirayama disease. PCEMs weakness is a cause of adolescent idiopathic kyphosis(38) .Extensor muscle strength is weaker than flexor muscle strength in people with poor cervical curvature, as has been reported for $\mathrm{HD}(23)$. The cervical spine is associated with PCEMs much like a "bow" and "string". Numerous studies have highlighted the importance of strengthening muscles for spinal sagittal balance $(30,39,40)$. Based on the above studies, we believe that strengthening the PCEMs should be an important part of HD treatment.

\section{Limitations}

There are some limitations in this study. First, the lack of patients make our data not meet the normality, so we could only use rank correlation, which reduces the level of evidence. Second, the study is limited by its retrospective nature as it lacks healthy controls. Thus, further studies are needed to support the theory we put forward. Finally, only the $\mathrm{C}_{5}-\mathrm{C}_{6}$ level was selected for the muscle area and a simplified measurement method was used, not the true cross-sectional area of the entire back of the neck muscles. Because some parameters of the cervical spine sagittal position are used to evaluate the overall condition of the cervical spine, and CSA does not represent the overall cervical extensor, even partial adjustment of the measurement indicators may affect our results.

\section{Conclusion}

In patients with Hirayama disease, the CSA of the PCEMs is related to T1s and local kyphotic angle. In Hirayama disease management, exercising the PCEMs should be emphasized.

\section{Abbreviations}

CSA: Cross-sectional area; HD: Hirayama disease; MRI: Magnetic resonance imagine; R-CSA: Relative cross-sectional area; ROI: Region of interest SEs: Superficial extensors; DEs: Deep extensors; PCEMs: Posterior cervical extensor muscles; VBA: Vertebral body area; LKD: Local kyphotic deformity

\section{Declarations}


The authors declare that they have no conflict of interest.

\section{Authors' contributions $\llbracket$}

Ye Tian and Lin Xie wrote the main manuscript text and data collection, Wang and Jiang prepared all figures and tables. All authors reviewed the manuscript.

\section{Funding:}

This study was supported by grants from Clinical Research Plan of SHDC『No. SHDC2020CR4030冈and Clinical Technology Innovation Project of SHDCXNo. SHDC12019X26》

\section{Availability of data and material:}

The dataset used and/or analysed during the current study are available from the corresponding author on reasonable request.

\section{Ethics approval and consent to participate囚}

The study was approved by the institutional ethics board (No:2021-582, Institutional Review Board of Huashan Hospital, Fudan University) and performed in accordance with the ethical standards of the 1964 Declaration of Helsinki as revised in 2000 and those of Good Clinical Practice.

All patients gave written informed consent. Participants under the age of 16 have obtained written informed consent from their parents or guardians.

\section{Conflict of interest:}

The authors declare that they have no conflict of interest.

\section{Acknowledgements:}

We thank the support from colleagues in our department.

\section{References}

1. Hirayama K. [Juvenile muscular atrophy of unilateral upper extremity (Hirayama disease)-halfcentury progress and establishment since its discovery]. Brain and nerve $=$ Shinkei kenkyu no shinpo. 2008;60(1):17-29. 
2. Antonioni A, Fonderico M, Granieri E. Hirayama Disease: A Case of an Albanian Woman Clinically Stabilized Without Surgery. Front Neurol. 2020;11:183.

3. Bogoni M, Teixeira BCA, Cioni M. Rare occurrence of Hirayama disease in Brazil. Arq Neuropsiquiatr. 2019;77(5):370-1.

4. Finsterer J, Loscher W, Wanschitz J, Baumann M, Quasthoff S, Grisold W. Hirayama disease in Austria. Joint Bone Spine. 2013;80(5):503-7.

5. Witiw CD, O'Toole JE. Electric shocks and weakness of the right hand in a young man: Hirayama disease. The Lancet. 2019;394(10199).

6. Song J, Cui ZY, Chen ZH, Jiang JY. Analysis of the Effect of Surgical Treatment for the Patients with Hirayama Disease from the Perspective of Cervical Spine Sagittal Alignment. World Neurosurg. 2020;133:e342-e7.

7. Wang HL, Wu YW, Song J, Jiang JY, Lu FZ, Ma XS, et al. Cortical Activation Changes in Hirayama Disease After Anterior Cervical Decompression and Fusion. World Neurosurg. 2018;116:e588-e94.

8. Paredes I, Esteban J, Ramos A, Gonzalez P, Rivas JJ. A severe case of Hirayama disease successfully treated by anterior cervical fusion. J Neurosurg Spine. 2014;20(2):191-5.

9. Zhang H, Wang S, Li Z, Shen R, Lin R, Wu W, et al. Anterior Cervical Surgery for the Treatment of Hirayama Disease. World Neurosurg. 2019;127:e910-e8.

10. Xu X, Han H, Gao H, Hou C, Fan D, Fu Y, et al. The increased range of cervical flexed motion detected by radiographs in Hirayama disease. Eur J Radiol. 2011;78(1):82-6.

11. Passias PG, Segreto FA, Bortz CA, Horn SR, Frangella NJ, Diebo BG, et al. Fatty Infiltration of Cervical Spine Extensor Musculature: Is there a Relationship With Cervical Sagittal Balance? Clin Spine Surg. 2018;31(10):428-34.

12. Panjabi MM, Cholewicki J, Nibu K, Grauer J, Babat LB, Dvorak J. Critical load of the human cervical spine: an in vitro experimental study. Clin Biomech (Bristol, Avon). 1998;13(1):11-7.

13. Song J, Wang HL, Zheng CJ, Jiang JY. Risk Factors for Surgical Results of Hirayama Disease: A Retrospective Analysis of a Large Cohort. World Neurosurg. 2017;105:69-77.

14. Yoon SY, Moon HI, Lee SC, Eun NL, Kim YW. Association between cervical lordotic curvature and cervical muscle cross-sectional area in patients with loss of cervical lordosis. Clin Anat. 2018;31(5):710-5.

15. Blazevich AJ, Coleman DR, Horne S, Cannavan D. Anatomical predictors of maximum isometric and concentric knee extensor moment. Eur J Appl Physiol. 2009;105(6):869-78.

16. Jones EJ, Bishop PA, Woods AK, Green JM. Cross-sectional area and muscular strength: a brief review. Sports Med. 2008;38(12):987-94.

17. Thakar S, Mohan D, Furtado SV, Sai Kiran NA, Dadlani R, Aryan S, et al. Paraspinal muscle morphometry in cervical spondylotic myelopathy and its implications in clinicoradiological outcomes following central corpectomy: clinical article. J Neurosurg Spine. 2014;21(2):223-30. 
18. Hou X, Lu S, Wang B, Kong C, Hu H. Morphologic Characteristics of the Deep Cervical Paraspinal Muscles in Patients with Single-Level Cervical Spondylotic Myelopathy. World Neurosurg. 2020;134:e166-e71.

19. Wang HL,Zheng C, Jin X,Lyu F,Ma XS, Xia X, et al. The Huashan diagnostic criteria and clinical classification of Hirayama disease. Chin J Orthop(Chinese).2019;39(8):458-65.

20. Nascimento OJ, Freitas MR. Non-progressive juvenile spinal muscular atrophy of the distal upper limb (Hirayama's disease): a clinical variant of the benign monomelic amyotrophy. Arq Neuropsiquiatr. 2000;58(3B):814-9.

21. Watanabe K, Hasegawa K, Hirano T, Endo N, Yamazaki A, Homma T. Anterior spinal decompression and fusion for cervical flexion myelopathy in young patients. J Neurosurg Spine. 2005;3(2):86-91.

22. Lyu F, Zheng C, Wang H, Nie C, Ma X, Xia X, et al. Establishment of a clinician-led guideline on the diagnosis and treatment of Hirayama disease using a modified Delphi technique. Clin Neurophysiol. 2020;131(6):1311-9.

23. Li Z, Zhang W, Wu W, Wei C, Chen X, Lin J. Is there cervical spine muscle weakness in patients with Hirayama disease? A morphological study about cross-sectional areas of muscles on MRI. European spine journal: official publication of the European Spine Society, the European Spinal Deformity Society, and the European Section of the Cervical Spine Research Society. 2020;29(5):1022-8.

24. Le Huec JC, Thompson W, Mohsinaly Y, Barrey C, Faundez A. Sagittal balance of the spine. Eur Spine J. 2019;28(9):1889-905.

25. Ling FP, Chevillotte T, Leglise A, Thompson W, Bouthors C, Le Huec JC. Which parameters are relevant in sagittal balance analysis of the cervical spine? A literature review. Eur Spine J. 2018;27(Suppl 1):8-15.

26. Murata K, Kenji E, Suzuki H, Takamatsu T, Nishimura H, Matsuoka Y, et al. Spinal Sagittal Alignment in Patients With Dropped Head Syndrome. Spine (Phila Pa 1976). 2018;43(21):E1267-E73.

27. Wen BT, Liu BG. Association between Changes in Sagittal X-ray Measurements and Neck Extensor Muscle Atrophy after Cervical Laminoplasty. Neurochirurgie. 2020;66(6):442-6.

28. Kwon B, Kim DH, Marvin A, Jenis LG. Outcomes following anterior cervical discectomy and fusion: the role of interbody disc height, angulation, and spinous process distance. J Spinal Disord Tech. 2005;18(4):304-8.

29. Lan Z, Huang Y, Xu W. Relationship Between T1 Slope Minus C2-7 Lordosis and Cervical Alignment Parameters After Adjacent 2-Level Anterior Cervical Diskectomy and Fusion of Lower Cervical Spine. World Neurosurg. 2019;122:e1195-e201.

30. Passias PG, Segreto FA, Bortz CA, Horn SR, Frangella NJ, Diebo BG, et al. Fatty Infiltration of Cervical Spine Extensor Musculature: Is there a Relationship With Cervical Sagittal Balance? Clinical spine surgery. 2018;31(10):428-34.

31. Kuo YH, Kuo CH, Chang HK, Fay LY, Tu TH, Chang CC, et al. The Effect of T1-Slope in Spinal Parameters After Cervical Disc Arthroplasty. Neurosurgery. 2020. 
32. Sun J, Zhao HW, Wang JJ, Xun L, Fu NX, Huang H. Diagnostic Value of T1 Slope in Degenerative Cervical Spondylotic Myelopathy. Med Sci Monit. 2018;24:791-6.

33. Lee S-H, Kim K-T, Seo E-M, Suk K-S, Kwack Y-H, Son E-S. The influence of thoracic inlet alignment on the craniocervical sagittal balance in asymptomatic adults. J Spinal Disord Tech. 2012;25(2):E41-E7.

34. Virk S, Lafage R, Elysee J, Louie P, Kim HJ, Albert T, et al. The 3 Sagittal Morphotypes That Define the Normal Cervical Spine: A Systematic Review of the Literature and an Analysis of Asymptomatic Volunteers. J Bone Joint Surg Am. 2020;102(19):e109.

35. Zhang J, Buser Z, Abedi A, Dong X, Wang JC. Can C2-6 Cobb Angle Replace C2-7 Cobb Angle?: An Analysis of Cervical Kinetic Magnetic Resonance Images and X-rays. Spine (Phila Pa 1976). 2019;44(4):240-5.

36. Harrison DE, Harrison DD, Cailliet R, Troyanovich SJ, Janik TJ, Holland B. Cobb method or Harrison posterior tangent method: which to choose for lateral cervical radiographic analysis. Spine. 2000;25(16):2072-8.

37. Wang H, Sun C, Yang S, Jiang J, Lu F, Ma X, et al. Dynamic Cervical Radiographs in Patients with Hirayama Disease: An Unneglectable Factor on the Choice of Surgery Options. World neurosurgery. 2018;114:e433-e40.

38. Xiaolong S, Xuhui Z, Jian C, Ye T, Wen Y. Weakness of the neck extensors, possible causes and relation to adolescent idiopathic cervical kyphosis. Med Hypotheses. 2011;77(3):456-9.

39. Hrysomallis C. Neck Muscular Strength, Training, Performance and Sport Injury Risk: A Review. Sports medicine (Auckland, NZ). 2016;46(8):1111-24.

40. Wen BT, Liu BG. Association between Changes in Sagittal X-ray Measurements and Neck Extensor Muscle Atrophy after Cervical Laminoplasty. Neuro-Chirurgie. 2020;66(6):442-6.

\section{Tables}

\section{Table 1}

\section{Parameters included in this study}




\begin{tabular}{|c|c|}
\hline Abbreviations & Definition \\
\hline CSA & Cross-sectional area \\
\hline VBA & Vertebral body area \\
\hline R-CSA & Relative cross-sectional area \\
\hline $\mathrm{CE}^{*}$ & cervical extensors \\
\hline SVA & sagittal vertical axis \\
\hline LKA & Local kyphosis angle \\
\hline CL & Cervical lordosis \\
\hline \multicolumn{2}{|c|}{ 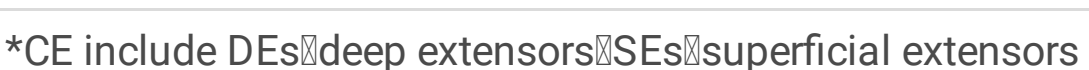 } \\
\hline
\end{tabular}

Table 2

Parametric results

\begin{tabular}{ll} 
Characteristics & Number* \\
\hline No. of patients & 60 \\
\hline Age $\searrow$ yr & $18.95 \pm 1.67$ \\
\hline CSA $\left(\mathrm{mm}^{2}\right)$ & $1348.98 \pm 236.44$ \\
\hline VBA $\left(\mathrm{mm}^{2}\right)$ & $384.62 \pm 64.70$ \\
\hline R-CSA & $3.60 \pm 0.87$ \\
\hline C2-C7 Cobb angle $\left(^{\circ}\right)$ & $5.28 \pm 12.43$ \\
\hline T1 Slope $\left(^{\circ}\right)$ & $16.62 \pm 5.96$ \\
\hline C2-C7 SVA $(\mathrm{mm})$ & $17.40 \pm 8.73$
\end{tabular}

*Values are presented as mean \pm SD

Table 3

Comparison of all parameters of different muscles in two groups 


\begin{tabular}{|c|c|c|c|c|}
\hline & $\operatorname{LKD}(\mathrm{n}=31)$ & Non-LKD(n=29) & T value & $\mathbf{P}$ value \\
\hline Height(cm) & $175.03 \pm 1.07$ & $173.10 \pm 1.27$ & 1.17 & 0.25 \\
\hline Weight(kg) & $64.18 \pm 2.018$ & $64.84 \pm 1.72$ & -0.25 & 0.80 \\
\hline $\mathrm{BMI}\left(\mathrm{kg} / \mathrm{m}^{2}\right)$ & $20.86 \pm 0.50$ & $21.68 \pm 0.57$ & -1.06 & 0.29 \\
\hline $\operatorname{CSA}\left(\mathrm{mm}^{2}\right)$ & $1348.52 \pm 236.24$ & $1349.47 \pm 240.85$ & -0.02 & 0.99 \\
\hline VBA囚mm² $\square$ & $401.46 \pm 72.62$ & $366.62 \pm 50.21$ & 2.15 & $0.04^{*}$ \\
\hline R-CSA & $3.45 \pm 0.79$ & $3.76 \pm 0.94$ & $\mathrm{a} Z=-1.22$ & 0.22 \\
\hline C2-C7 Cobb angle $\left(^{\circ}\right)$ & $-1.41 \pm 8.19$ & $12.40 \pm 12.32$ & a $Z=-4.42$ & $0.00 * \star$ \\
\hline T1 Slope $\left(^{\circ}\right)$ & $15.23 \pm 5.54$ & $18.11 \pm 5.91$ & -1.94 & 0.06 \\
\hline C2-C7 SVA (mm) & $17.37 \pm 7.72$ & $17.43 \pm 9.85$ & -0.02 & 0.98 \\
\hline
\end{tabular}

\section{Figures}

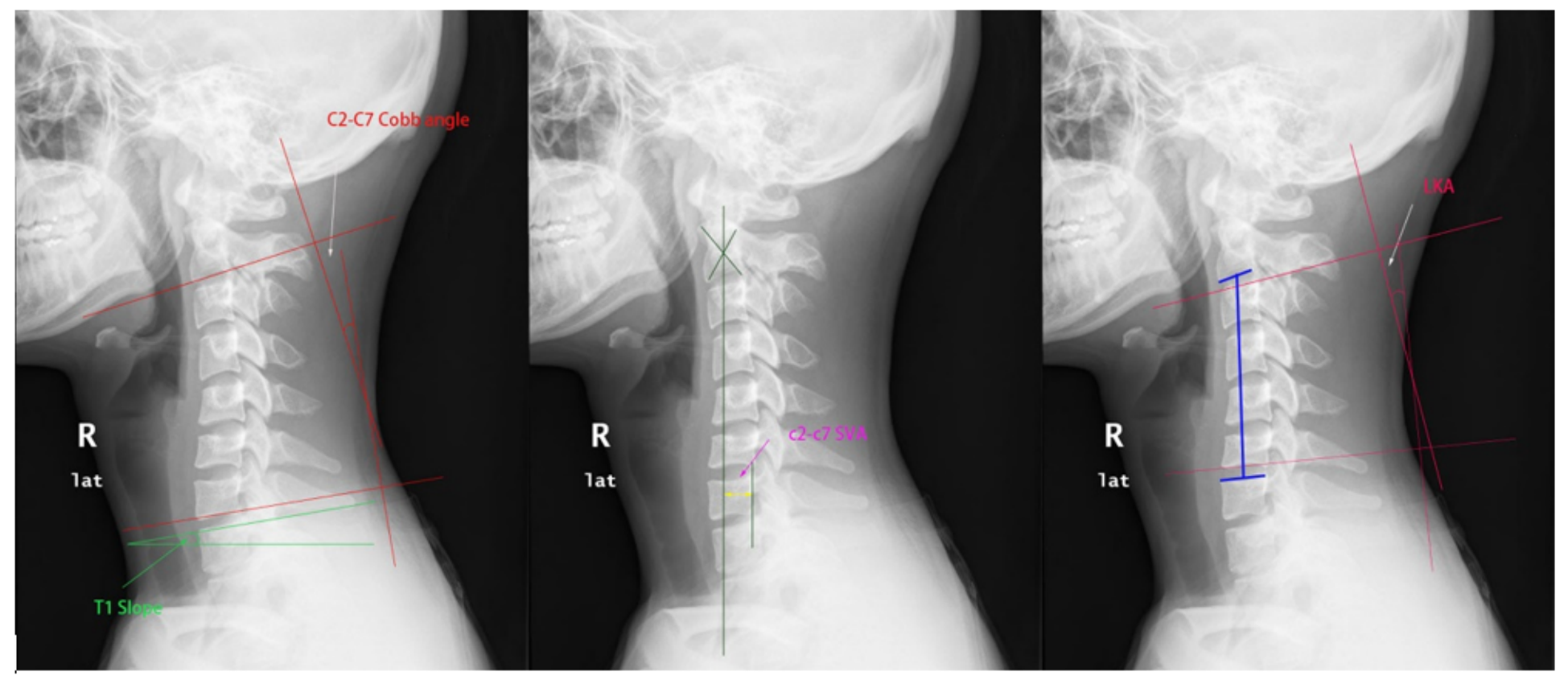

Figure 1

Figure 1 
Cervical sagittal parameters were measured on upright cervical radiographs(Figure 1).
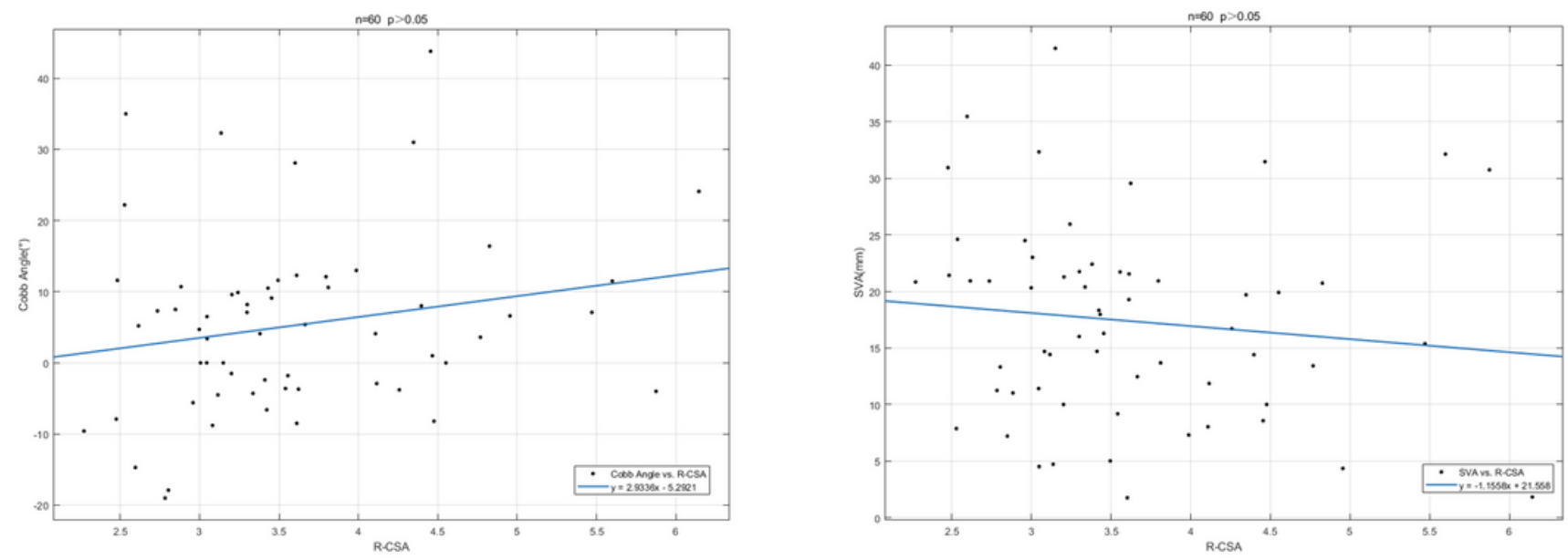

(a)

(b)
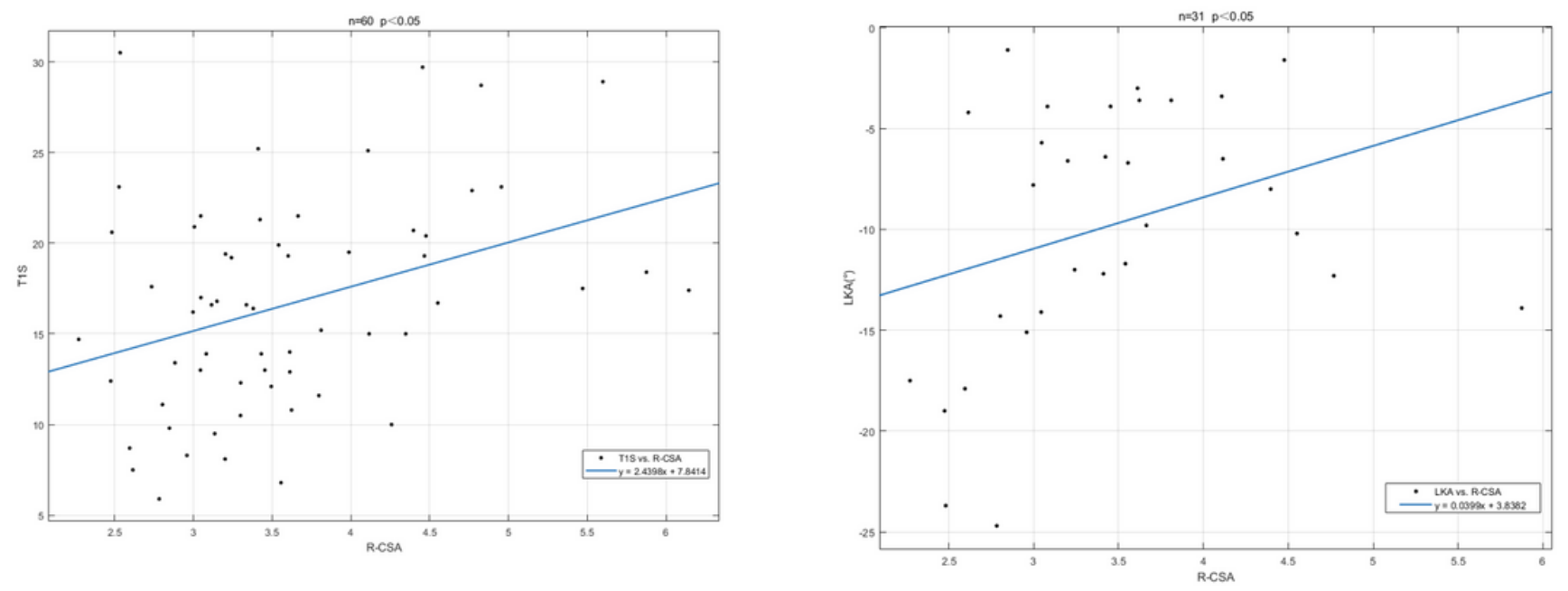

(c)

(d)

Figure 2

\section{Figure 2}

Correlation analyses were done using Spearman test. R-CSA negatively correlated with T1S ( $\mathrm{s}=0.3362$, $p=0.0086) R-C S A$ negatively correlated with LKA $(s=0.4382, p=0.0137) \cdot R-C S A$ did not correlate with C2-C7 cobb angle $(s=0.2029, p=0.1199)$ or $C 2-C 7$ SVA $(s=-0.1701, p=0.4586)$.(Figure2) 


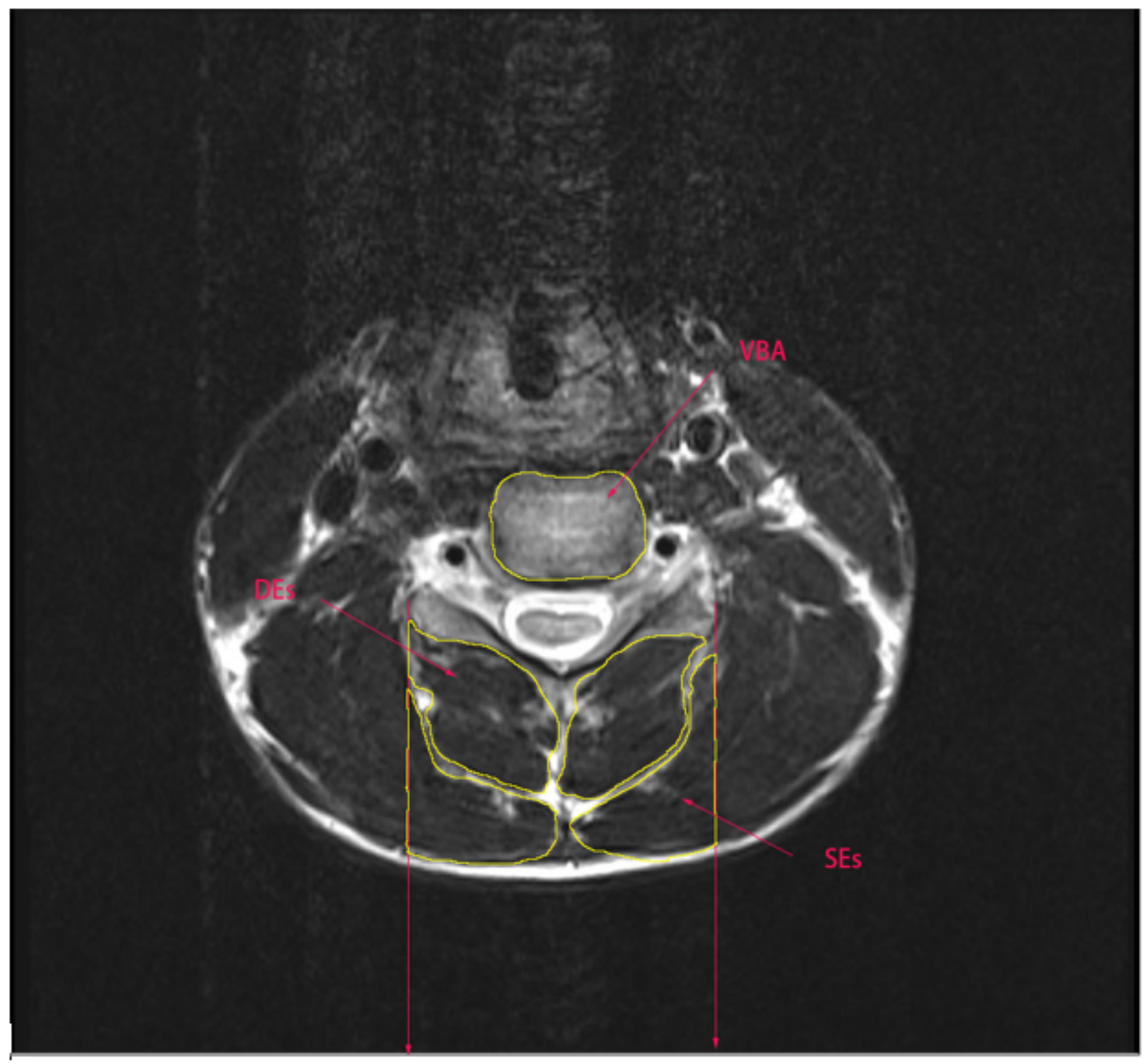

\section{Figure3}

\section{Figure 3}

Muscle cross-sectional area was measured by 2 independent spine surgeons(Table 1), Tian and Xie, using the Image J(National Institutes of Health, America) to measure ROI (Figure 3) on the CSA of the PCEMs based on the techniques used in previous studies(23). 